\title{
Generalized coupling resonance modeling, analysis, and active damping of multi-parallel inverters in microgrid operating in grid-connected mode
}

\author{
Zhiyong CHEN ${ }^{1}$, Yandong CHEN ${ }^{1}$, Josep M. GUERRERO ${ }^{2}$, \\ Huimin KUANG ${ }^{1}$, Yuan HUANG ${ }^{1}$, Leming ZHOU ${ }^{1}$, \\ An LUO ${ }^{1}$
}

\begin{abstract}
This paper firstly presents an equivalent coupling circuit modeling of multi-parallel inverters in microgrid operating in grid-connected mode. By using the model, the coupling resonance phenomena are explicitly investigated through the mathematical approach, and the intrinsic and extrinsic resonances exist widely in microgrid. Considering the inverter own reference current, other inverters reference current, and grid harmonic voltage, the distributions of resonance peaks with the growth in the number of inverters are obtained. Then, an active damping control parameter design method is proposed to attenuate coupling resonance, and the most salient feature is that the optimal range of the damping parameter can be easily located through an initiatively graphic method. Finally, simulations and experiments verify the validity of the proposed modeling and method.
\end{abstract}

Keywords Microgrid, Grid-connected mode, Multiparallel inverters, Active damping, Coupling resonance

CrossCheck date: 21 December 2015

Received: 14 November 2015/Accepted: 28 December 2015/ Published online: 19 January 2016

(C) The Author(s) 2016. This article is published with open access at Springerlink.com

$\triangle$ Yandong CHEN

xlcyd520@163.com

Zhiyong CHEN

chenzhiyong2008bj@126.com

Josep M. GUERRERO

joz@et.aau.dk

Huimin KUANG

huiminkuang@163.com

\section{Introduction}

Distributed generation (DG) units such as wind turbines and solar cell panels are integrated into distribution networks by power electronic switches $[1,2]$. As a consequence of the increasing penetration of DG units in local grids, the concept of microgrid has gained popularity. Microgrid has ability to operate in both islanded and gridconnected modes [3-5]. The former, droop control methods $[5,6]$ are used to guarantee the accuracy of power sharing among DG units. The latter, current control schemes with maximum power-point tracking (MPPT) algorithms are implemented to maximize power supply to the grid [7-9].

The $\mathrm{L}$ and LCL filters are widely used in grid-connected inverters, while the LC filter is mostly applied in uninterruptible power supplies or islanded microgrids $[10,11]$. The LCL filter performs a better ability to attenuate highorder harmonics than the L filter. Nevertheless, the LCL filter has an inherent resonance peak which significantly magnifies the harmonic current around its peak frequency. Therefore, active damping methods should be used to reduce the current distortion. The most common control

Yuan HUANG

hy_8615381@163.com

Leming ZHOU

leming_zhou@126.com

An LUO

an_luo@126.com

1 National Electric Power Conversion and Control Engineering Technology Research Center, Hunan University, Changsha, China

2 Department of Energy Technology, Aalborg University, Aalborg East 9220, Denmark 
structures which include active damping can be categorized into: (1) cascaded dual-loop [12], consisting of a grid-sidecurrent outer loop and an inner active-damping loop; (2) single loop with inner feedback [13-15], consisting of a grid-side-current outer loop and an active-damping inner feedback loop.

In the dual-loop control system, the closed-loop stability can be guaranteed by sophisticatedly designing the inner and outer loop parameters. However, these parameters are coupled with each other. Thus, it makes the tuning procedure more difficult. To completely decouple the control parameters, the control structure of single loop with inner feedback is a feasible solution. By this way, the control parameters without coupling can be easily to acquire. For the inner feedback, the filter-capacitor current is more favorable than the inverter-side current [15]. The latter equals to place virtual impedance connecting in series with inverter-side inductor, which will deteriorate the frequency dynamics of output filter.

The resonance phenomena among multi-parallel inverters are more complicated than the case of single one [16]. To explaining the coupling resonance phenomena, the parallel and series resonances should be investigated as a whole. For this reason, a simplified explanation of these resonances among multi-parallel inverters is presented in [17]. And the discussion about series and parallel resonances in wideband frequency domain is presented in [18].

In this paper, an equivalent coupling resonance model of multi-parallel inverters in microgrid operating in grid-connected mode is presented, and the coupling resonance phenomena are explicitly investigated through the mathematical approach. To attenuate coupling resonance, an active damping control parameter design method is proposed. The rest of the paper is organized as follows. Firstly, an equivalent coupling resonance model is built, and the resonance peaks among multi-parallel inverters are explicitly investigated through the mathematical approach in Sect. 2. Secondly, the intrinsic and extrinsic resonances in the different number of inverters are analyzed in detail in Sect. 3. Then, an active damping control parameter design method is proposed to attenuate coupling resonance, and the optimal range of the damping parameter can be easily located through an initiatively graphic method in Sect. 4. Finally, simulations and experimental results verify the correctness of the modeling and also confirm the feasibility of the proposed approach in Sect. 5. Some conclusions are given out in Sect. 6.

\section{Equivalent coupling modeling of multiple- parallel inverters}

Figure 1 shows the power stage and control diagram of multiple-parallel inverters in the microgrid operating in grid-connected mode. Each DG unit consists of several

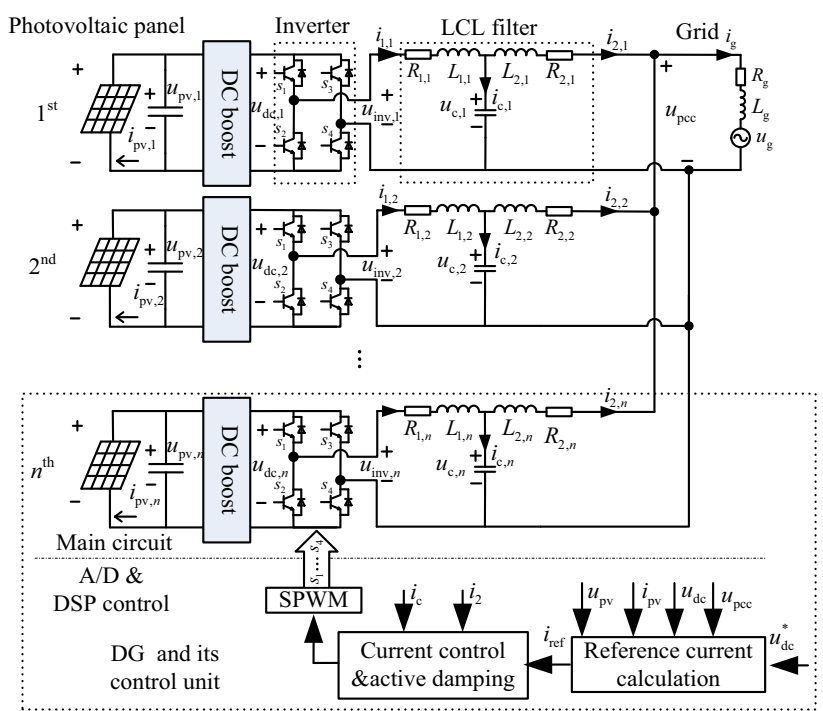

Fig. 1 Power stage and control diagram of a cluster of photovoltaic inverters

photovoltaic panels, a DC/DC boost converter, an H-bridge inverter, and a LCL filter.

Subscript $n$ is the $n^{\text {th }}$ inverter; Superscript $*$ is the reference of a signal; $u_{\mathrm{dc}}$ is the DC link voltage; $u_{\mathrm{inv}}$ is the inverter output voltage; $R_{1}, R_{2}$ are the inverter-side and grid-side equivalent resistances of the filter; $\mathrm{C}_{\mathrm{f}}$ is the filter capacitor; $L_{1}, L_{2}$ are the inverter-side and grid-side inductors of filter; $i_{1}, i_{2}, i_{\mathrm{c}}$ are the inverter-side current, grid-side inductor current, and filter-capacitor current, respectively; $i_{\text {ref }}$ is the inverter reference current; $u_{\mathrm{pcc}}$ is the point of common coupling (PCC) voltage; $u_{\mathrm{g}}$ is the grid voltage; $i_{\mathrm{g}}$ is the grid current; $R_{\mathrm{g}}, L_{\mathrm{g}}$ are the equivalent resistance and inductance of the grid.

To simplify the analysis, the photovoltaic panel and its DC/DC boost converter can be regarded as a DC voltage source. The block of reference current calculation in Fig. 1, is used to obtain $i_{\text {ref }}$. For the interested reader, further discussion on how to obtain the value of $i_{\text {ref }}$ can be found in $[8,9]$, and will not be repeated in this paper.

Figure 2 shows the block diagram of current control and active damping from Fig. 1. The control structure consists of grid-side-current outer loop and filter-capacitor-current inner feedback. $K_{\mathrm{pwm}}$ is the inverter switch gain and $K_{\mathrm{pwm}}=u_{\mathrm{dc}} / u_{\mathrm{tri}}$, where $u_{\text {tri }}$ is the amplitude of triangular carrier. To enhance the control accuracy, as well as 
improve attenuation ability of low-order harmonics, the proportional resonant (PR) controller takes account of the fundamental, $3^{\text {rd }}, 5^{\text {th }}, 7^{\text {th }}, 9^{\text {th }}$, and $11^{\text {th }}$ harmonic currents. The objective of the inner feedback loop is to guarantee the active damping effect on the inherent resonance of the filter, and $K_{\mathrm{C}}$ is the coefficient of damping feedback.

The Norton equivalent model of inverter control system can be deduced from Fig. 1, and expressed as

$I_{2}(s)=G_{\mathrm{cs}}(s) I_{\mathrm{ref}}(s)-Y_{\mathrm{cs}} U_{\mathrm{pcc}}(s)$

where $G_{\mathrm{cs}}(s)$ and $Y_{\mathrm{cs}}(s)$ are the equivalent current source coefficient and equivalent admittance, and expressed as follows.

$$
\begin{aligned}
\frac{I_{2}(s)}{I_{\mathrm{ref}}(s)} & =G_{\mathrm{cs}}(s) \\
& =\frac{K_{\mathrm{PWM}} G_{\mathrm{PR}} G_{1} G_{\mathrm{c}} G_{2}}{1+H_{\mathrm{d}} G_{\mathrm{c}}+G_{1} G_{\mathrm{c}}+G_{\mathrm{c}} G_{2}+K_{\mathrm{PWM}} G_{\mathrm{PR}} G_{1} G_{\mathrm{c}} G_{2}}
\end{aligned}
$$

$$
\begin{aligned}
\frac{I_{2}(s)}{U_{\mathrm{pcc}}(s)} & =Y_{\mathrm{cs}}(s) \\
& =-\frac{G_{2}+H_{\mathrm{d}} G_{\mathrm{c}} G_{2}+G_{1} G_{\mathrm{c}} G_{2}}{1+H_{\mathrm{d}} G_{\mathrm{c}}+G_{1} G_{\mathrm{c}}+G_{\mathrm{c}} G_{2}+K_{\mathrm{PWM}} G_{\mathrm{PR}} G_{1} G_{\mathrm{c}} G_{2}}
\end{aligned}
$$

where $H_{\mathrm{d}}=K_{\mathrm{PWM}} K_{\mathrm{C}} C_{\mathrm{f}} / L_{1} ; \quad G_{1}=1 /\left(s L_{1}+R_{1}\right) ; \quad G_{\mathrm{c}}=1 /$ $s C_{\mathrm{f}} ; G_{2}=1 /\left(s L_{2}+R_{2}\right) ; G_{\mathrm{PR}}$ is the transfer function of PR controller, and expressed as
$G_{\mathrm{PR}}=K_{p}+\sum_{h=1,3,5,7,9,11} \frac{2 k_{\mathrm{i}, \mathrm{h}} \omega_{\mathrm{c}} s}{s^{2}+2 \omega_{\mathrm{c}} s+h^{2} \omega_{\mathrm{n}}^{2}}$

where $K_{\mathrm{p}}$ and $k_{\mathrm{i}, h}$ are the proportional and the $h^{\text {th }}$ resonant gains of the PR controller; $\omega_{\mathrm{c}}$ is the cut-off frequency; $\omega_{\mathrm{n}}$ is the fundamental frequency; $h$ is the harmonic order.

Figure 3 shows the equivalent circuit of multi-parallel inverters. $Y_{\mathrm{g}}$ is the grid equivalent admittance.

The voltage equation associated with the node of $U_{\mathrm{pcc}}$ in Fig. 3 can be written as

$$
\begin{aligned}
& \left(Y_{\mathrm{cs}, 1}+\cdots+Y_{\mathrm{cs}, \mathrm{n}}\right) U_{\mathrm{pcc}}+Y_{\mathrm{g}} U_{\mathrm{pcc}} \\
& \quad=\left(G_{\mathrm{cs}, 1} I_{\mathrm{ref}, 1}+\cdots+G_{\mathrm{cs}, \mathrm{n}} I_{\mathrm{ref}, \mathrm{n}}\right)+Y_{\mathrm{g}} U_{\mathrm{g}}
\end{aligned}
$$

As far as the $m^{\text {th }}$ inverter $(1 \leq m \leq n)$ is considered, (1) can be rewritten as

$I_{2, m}(s)=G_{\mathrm{cs}, m}(s) I_{\mathrm{ref}, m}(s)-Y_{\mathrm{cs}, m} U_{\mathrm{pcc}}(s)$

By substituting (6) into (5), $I_{2, m}$ can be explained as

$I_{2, m}=\Phi_{\text {ind }, m} I_{\mathrm{ref}, m}-\sum_{i=1, i \neq m}^{n} \Phi_{\mathrm{para}, m, i} I_{\mathrm{ref}, i}-\Phi_{\text {series }, m} U_{g}$

where the subscripts $i$ and $m$ are the $i^{\text {th }}$ and $m^{\text {th }}$ inverter; $\Phi_{\text {ind, } m}$ is the relationship between $I_{2, m}$ and $I_{\text {ref }, m} ; \Phi_{\text {para }, m, i}$ is the relationship between $I_{2, m}$ and $I_{\text {ref }, i} ; \Phi_{\text {series }, m}$ is the relationship between $I_{2, m}$ and $U_{\mathrm{g}}$.

$$
\begin{aligned}
& \Phi_{\text {ind },} m=\frac{K_{\mathrm{PWM}, m} G_{\mathrm{PR}, m} G_{1, m} G_{\mathrm{c}, m} G_{2, m}}{1+H_{\mathrm{d}, m} G_{\mathrm{c}, m}+G_{1, m} G_{\mathrm{c}, m}+G_{\mathrm{c}, m} G_{2, m}+K_{\mathrm{PWM}, m} G_{\mathrm{PR}, m} G_{1, m} G_{\mathrm{c}, m} G_{2, m}} \bullet \\
& \sum_{i=1}^{n}\left(\begin{array}{c}
1-\frac{1+H_{\mathrm{d}, i} G_{\mathrm{c}, i}+G_{1, i} G_{\mathrm{c}, i}+G_{\mathrm{c}, i} G_{2, i}+K_{\mathrm{PWM}, i} G_{\mathrm{PR}, i} G_{1, i} G_{\mathrm{c}, i} G_{2, i}}{G_{2, i}+H_{\mathrm{d}, i} G_{\mathrm{c}, i} G_{2, i}+G_{1, i} G_{\mathrm{c}, i} G_{2, i}+Y_{\mathrm{g}}\left(1+H_{\mathrm{d}, i} G_{\mathrm{c}, i}+G_{1, i} G_{\mathrm{c}, i}+G_{\mathrm{c}, i} G_{2, i}+K_{\mathrm{PWM}, i} G_{\mathrm{PR}, i} G_{1, i} G_{\mathrm{c}, i} G_{2, i}\right)} \\
\frac{G_{2, m}+H_{d, m} G_{c, m} G_{2, m}+G_{1, m} G_{c, m} G_{2, m}}{1+H_{\mathrm{d}, m} G_{\mathrm{c}, m}+G_{1, m} G_{\mathrm{c}, m}+G_{\mathrm{c}, m} G_{2, m}+K_{\mathrm{PWM}, m} G_{\mathrm{PR}, m} G_{1, m} G_{\mathrm{c}, m} G_{2, m}}
\end{array}\right)
\end{aligned}
$$

$$
\begin{aligned}
& \Phi_{\mathrm{para}, m, i}=\frac{\frac{G_{2, m}+H_{\mathrm{d}, m} G_{\mathrm{c}, m} G_{2, m}+G_{1, m} G_{\mathrm{c}, m} G_{2, m}}{1+H_{\mathrm{d}, m} G_{\mathrm{c}, m}+G_{1, m} G_{\mathrm{c}, m}+G_{\mathrm{c}, m} G_{2, m}+K_{\mathrm{PWM}, m} G_{\mathrm{PR}, m} G_{1, m} G_{\mathrm{c}, m} G_{2, m}}}{\sum_{i=1}^{n} \frac{G_{2, i}+H_{\mathrm{d}, i} G_{\mathrm{c}, i} G_{2, i}+G_{1, i} G_{\mathrm{c}, i} G_{2, i}+Y_{g}\left(1+H_{\mathrm{d}, i} G_{\mathrm{c}, i}+G_{1, i} G_{\mathrm{c}, i}+G_{\mathrm{c}, i} G_{2, i}+K_{\mathrm{PWM}, i} G_{\mathrm{PR}, i} G_{1, i} G_{\mathrm{c}, i} G_{2, i}\right)}{\left(1+H_{\mathrm{d}, i} G_{\mathrm{c}, i}+G_{1, i} G_{\mathrm{c}, i}+G_{\mathrm{c}, i} G_{2, i}+K_{\mathrm{PWM}, i} G_{\mathrm{PR}, i} G_{1, i} G_{\mathrm{c}, i} G_{2, i}\right)}} \bullet \\
& \sum_{i=1, i \neq m}^{n} \frac{K_{\mathrm{PWM}, i} G_{\mathrm{PR}, i} G_{1, i} G_{\mathrm{c}, i} G_{2, i}}{1+H_{\mathrm{d}, i} G_{\mathrm{c}, i}+G_{1, i} G_{\mathrm{c}, i}+G_{\mathrm{c}, i} G_{2, i}+K_{\mathrm{PWM}, i} G_{\mathrm{PR}, i} G_{1, i} G_{\mathrm{c}, i} G_{2, i}} I_{\mathrm{ref}, i}
\end{aligned}
$$




$$
\begin{aligned}
\Phi_{\mathrm{series}, m}= & \frac{G_{2, m}+H_{\mathrm{d}, m} G_{\mathrm{c}, m} G_{2, m}+G_{1, m} G_{\mathrm{c}, m} G_{2, m}}{1+H_{\mathrm{d}, m} G_{\mathrm{c}, m}+G_{1, m} G_{\mathrm{c}, m}+G_{\mathrm{c}, m} G_{2, m}+K_{\mathrm{PWM}, m} G_{\mathrm{PR}, m} G_{1, m} G_{\mathrm{c}, m} G_{2, m}} \bullet \\
& \sum_{i=1}^{\mathrm{n}} \frac{Y_{\mathrm{g}}\left(1+H_{d, i} G_{\mathrm{c}, i}+G_{1, i} G_{\mathrm{c}, i}+G_{\mathrm{c}, i} G_{2, i}+K_{\mathrm{PWM}, i} G_{\mathrm{PR}, i} G_{1, i} G_{\mathrm{c}, i} G_{2, i}\right)}{G_{2, i}+H_{\mathrm{d}, i} G_{\mathrm{c}, i} G_{2, i}+G_{1, i} G_{\mathrm{c}, i} G_{2, i}+Y_{\mathrm{g}}\left(1+H_{\mathrm{d}, i} G_{\mathrm{c}, i}+G_{1, i} G_{\mathrm{c}, i}+G_{\mathrm{c}, i} G_{2, i}+K_{\mathrm{PWM}, i} G_{\mathrm{PR}, i} G_{1, i} G_{\mathrm{c}, i} G_{2, i}\right)}
\end{aligned}
$$

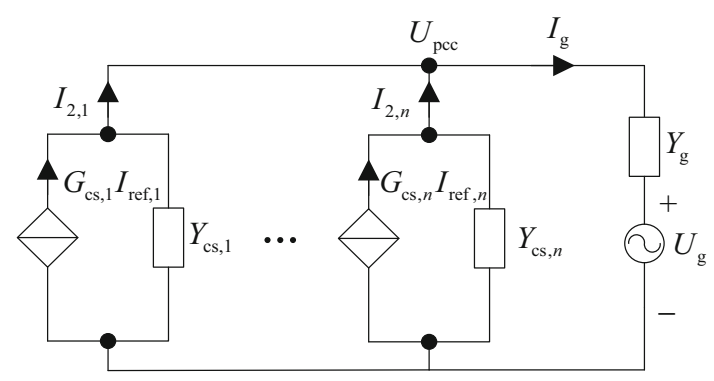

Fig. 3 Equivalent circuit of multi-parallel inverters in microgrid operating in grid-connected mode

Seen from (7), three factors impact directly grid-side current of an inverter, including (1) its own inverter reference current; (2) the reference currents of other inverters; (3) the grid voltage.

Figure 4 shows the equivalent coupling circuit of multiparallel inverters.

Taking $I_{2,1}$ for example, Fig. 4 indicates that $I_{2,1}$ is produced by the currents superposition from $n+1$ branches,

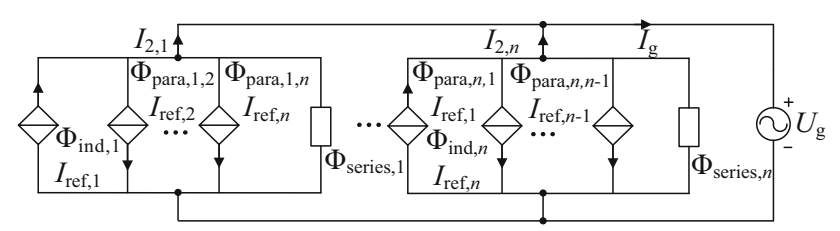

Fig. 4 Equivalent coupling circuit of multi-parallel inverters in microgrid operating in grid-connected mode
i.e.,
(1) $\Phi_{\text {ind, } 1} I_{\text {ref }, 1}$
(2) $\Phi_{\mathrm{para}, m, i} I_{\mathrm{ref}, i}$
$(i=2,3, \ldots, n)$
(3) $\Phi_{\text {series }, 1}$.

\section{Analysis and distributions of coupling resonance peaks considering three factors impact}

It is reasonable to suppose that each DG unit is equivalent. Therefore, the elements in (7) can be expressed as reduced-order forms, and rewritten as

$$
\begin{aligned}
\Phi_{\mathrm{ind}, m}= & \frac{K_{\mathrm{PWM}, m} G_{\mathrm{PR}, m} G_{1, m} G_{\mathrm{c}, m} G_{2, m}}{1+H_{\mathrm{d}, m} G_{\mathrm{c}, m}+G_{1, m} G_{\mathrm{c}, m}+G_{\mathrm{c}, m} G_{2, m}+K_{\mathrm{PWM}, m} G_{\mathrm{PR}, m} G_{1, m} G_{\mathrm{c}, \mathrm{m}} G_{2, m}} \\
& \bullet \\
& \left(n-\frac{n\left(G_{2, m}+H_{\mathrm{d}, m} G_{\mathrm{c}, \mathrm{m}} G_{2, m}+G_{1, m} G_{\mathrm{c}, m} G_{2, m}\right)}{\left(G_{2, m}+H_{\mathrm{d}, m} G_{\mathrm{c}, m} G_{2, m}+G_{1, m} G_{\mathrm{c}, m} G_{2, m}+Y_{\mathrm{g}}\left(1+H_{\mathrm{d}, m} G_{\mathrm{c}, m}+G_{1, m} G_{\mathrm{c}, m}+G_{\mathrm{c}, m} G_{2, m}+K_{\mathrm{PWM}, m} G_{\mathrm{PR}, m} G_{1, m} G_{\mathrm{c}, m} G_{2, m}\right)\right)}\right)
\end{aligned}
$$

$\Phi_{\mathrm{para}, m, i}=\frac{G_{2, m}+H_{\mathrm{d}, m} G_{\mathrm{c}, m} G_{2, m}+G_{1, m} G_{\mathrm{c}, m} G_{2, m}}{1+H_{\mathrm{d}, m} G_{\mathrm{c}, m}+G_{1, m} G_{\mathrm{c}, m}+G_{\mathrm{c}, m} G_{2, m}+K_{\mathrm{PWM}, m} G_{\mathrm{PR}, m} G_{1, m} G_{\mathrm{c}, \mathrm{m}} G_{2, m}} \bullet$

$$
\frac{K_{\mathrm{PWM}, i} G_{\mathrm{PR}, i} G_{1, i} G_{\mathrm{c}, i} G_{2, i}}{G_{2, i}+H_{\mathrm{d}, i} G_{\mathrm{c}, i} G_{2, i}+G_{1, i} G_{\mathrm{c}, i} G_{2, i}+Y_{\mathrm{g}}\left(1+H_{\mathrm{d}, i} G_{\mathrm{c}, i}+G_{1, i} G_{\mathrm{c}, i}+G_{\mathrm{c}, i} G_{2, i}+K_{\mathrm{PWM}, i} G_{\mathrm{PR}, i} G_{1, i} G_{\mathrm{c}, i} G_{2, i}\right)} I_{\mathrm{ref}, i}
$$

$\Phi_{\text {series }, m}=\frac{n\left(G_{2, m}+H_{\mathrm{d}, m} G_{\mathrm{c}, m} G_{2, m}+G_{1, m} G_{\mathrm{c}, m} G_{2, m}\right) Y_{\mathrm{g}}}{G_{2, i}+H_{\mathrm{d}, i} G_{\mathrm{c}, i} G_{2, i}+G_{1, i} G_{\mathrm{c}, i} G_{2, i}+Y_{\mathrm{g}}\left(1+H_{\mathrm{d}, i} G_{\mathrm{c}, i}+G_{1, i} G_{\mathrm{c}, i}+G_{\mathrm{c}, i} G_{2, i}+K_{\mathrm{PWM}, i} G_{\mathrm{PR}, i} G_{1, i} G_{\mathrm{c}, i} G_{2, i}\right)}$ 


\subsection{Mathematical approach to describe resonance peaks}

According to the simulation parameters listed in Table 1, the inherent resonance peak of the filter is around $35^{\text {th }}$ harmonic frequency. The frequency interval chooses within $\left(0,40 \omega_{\mathrm{n}}\right]$.

The mathematical approach to search the peak frequencies of the resonances among multi-parallel inverters can be described as finding the local maxima of the functions $\Phi_{\text {ind }}(\mathrm{j} \omega), \Phi_{\text {para }}(\mathrm{j} \omega)$, and $\Phi_{\text {series }}(\mathrm{j} \omega)$.

According to the first derivative test in calculus, the precise statement of a resonance peak in a specific frequency domain can be described as: Suppose a transfer function $\Phi(\mathrm{j} \omega)$ defined on the left-open-right-closed interval of $\left(0,40 \omega_{\mathrm{n}}\right]$; Further suppose that $\Phi(\mathrm{j} \omega)$ is continuous at $\omega_{\mathrm{R}}$ and differentiable on some open interval containing $\omega_{\mathrm{R}}$, except possibly at $\omega_{\mathrm{R}}$ itself; If there exist a positive number $\Delta \omega$ such that for every $\omega$ in $\left(\omega_{R}-\Delta \omega, \omega_{R}\right]$ we have $\mathrm{d}|\Phi(\mathrm{j} \omega)| / \mathrm{d} \omega \geq 0$, and for every $\omega$ in $\left[\omega_{R}, \omega_{R}+\Delta \omega\right)$ we have $\mathrm{d}|\Phi(\mathrm{j} \omega)| / \mathrm{d} \omega \leq 0$, then $\Phi(\mathrm{j} \omega)$ has a local maximum at $\omega_{\mathrm{R}}$. In other words, $\omega_{\mathrm{R}}$ is a resonance frequency which cause the amplitude-frequency response of $\Phi(\mathrm{j} \omega)$ to reach its peak. In addition, according to (7), the resonance phenomena caused by $\Phi_{\text {ind, } m}$, $\Phi_{\text {series }, m}$, and $\Phi_{\text {para }, m, i}$ are individual, parallel, and series resonances, respectively.

Further, supposing that each inverter is equivalent, the value of $\mathrm{d}\left|\Phi_{\text {ind }}(\mathrm{j} \omega)\right| / \mathrm{d} \omega$, d $\left|\Phi_{\text {para }}(\mathrm{j} \omega)\right| / \mathrm{d} \omega$, and $\mathrm{d}\left|\Phi_{\text {series }}(\mathrm{j} \omega)\right| /$ $\mathrm{d} \omega$ in the frequency domain of $\left(\omega_{\mathrm{n}}, 40 \omega_{\mathrm{n}}\right)$, along with the variation in the number of parallel inverters are depicted in Fig. 5. Obviously, a local maximum of $\Phi(\mathrm{j} \omega)$ locates at the position where $\mathrm{d}|\Phi(\mathrm{j} \omega)| / \mathrm{d} \omega$ drastically switches from a

Table 1 Simulating and experimental parameters of multi-parallel inverters

\begin{tabular}{ll}
\hline Parameters & Values \\
\hline Inverter-side inductor $L_{1}$ & $5 \mathrm{mH}$ \\
Inverter-side equivalent resistance $R_{1}$ & $0.2 \Omega$ \\
Grid-side inductor $L_{2}$ & $1 \mathrm{mH}$ \\
Grid-side equivalent resistance $R_{2}$ & $0.2 \Omega$ \\
Filter capacitor $C_{\mathrm{f}}$ & $10 \mu \mathrm{F}$ \\
Grid equivalent inductance $L_{\mathrm{g}}$ & $1.2 \mathrm{mH}$ \\
Grid equivalent resistance $R_{\mathrm{g}}$ & $0.2 \Omega$ \\
DC link voltage $u_{\mathrm{dc}}$ & $400 \mathrm{~V}$ \\
Grid voltage (RMS) $u_{\mathrm{g}}$ & $220 \mathrm{~V}$ \\
Proportional gain $(\mathrm{PR}) K_{\mathrm{p}}$ & 2.1 \\
Integral gain $(\mathrm{PR}) k_{\mathrm{i}, 1} / k_{\mathrm{i}, 3} / k_{\mathrm{i}, 5}$ & $175 / 50 / 15$ \\
Integral gain $(\mathrm{PR}) k_{\mathrm{i}, 7} / k_{\mathrm{i}, 9} / k_{\mathrm{i}, 11}$ & $10 / 10 / 10$ \\
Cut-off angular frequency $(\mathrm{PR}) \omega_{\mathrm{c}}$ & $6.28 \mathrm{rad} / \mathrm{s}$ \\
Fundamental angular frequency $(\mathrm{PR}) \omega_{\mathrm{n}}$ & $314 \mathrm{rad} / \mathrm{s}$ \\
Inverter switching frequency $f_{\mathrm{sw}}$ & $12.8 \mathrm{kHz}$ \\
\hline
\end{tabular}

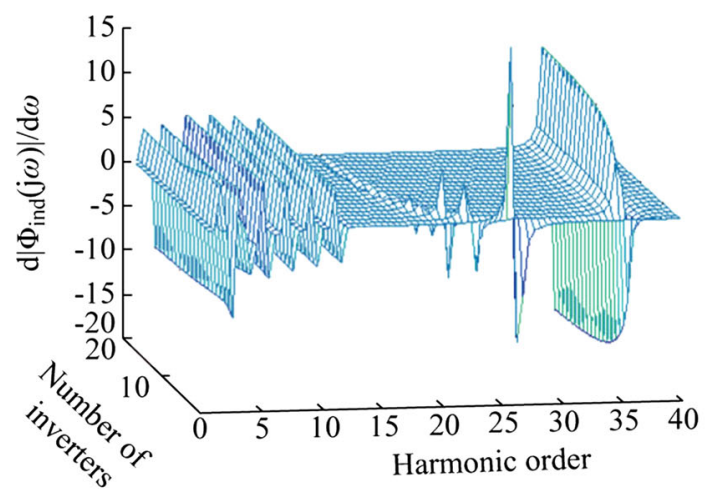

(a) $\mathrm{d}\left|\Phi_{\text {ind }}(\mathrm{j} \omega)\right| / \mathrm{d} \omega$

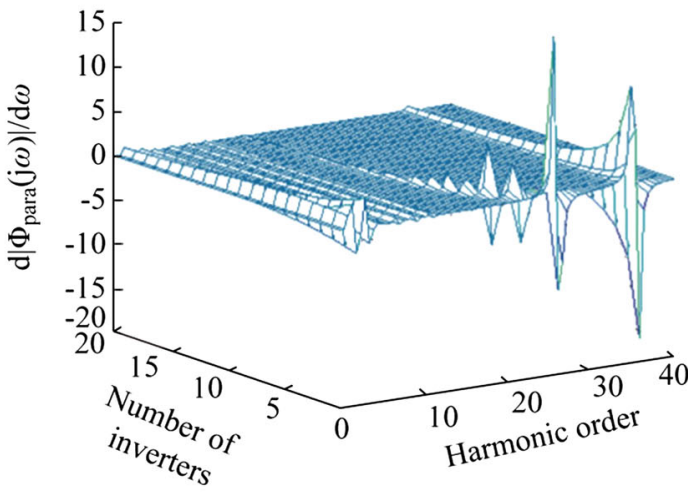

(b) $\mathrm{d}\left|\Phi_{\text {para }}(\mathrm{j} \omega)\right| / \mathrm{d} \omega$

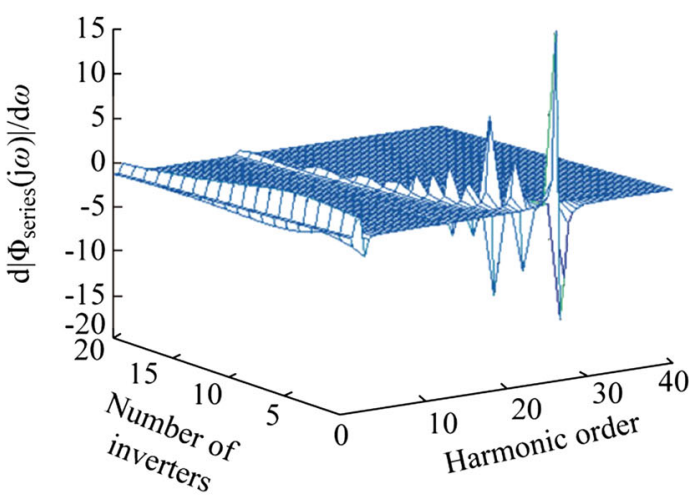

(c) $\mathrm{d}\left|\Phi_{\text {series }}(\mathrm{j} \omega)\right| / \mathrm{d} \omega$

Fig. 5 Distribution of resonance peaks

positive to a negative value. The $\omega_{\mathrm{R}}$ (the harmonic order multiplying by $\omega_{\mathrm{n}}$ ) and $n$ (number of inverters) associated with this local maximum are indicated that the $n$ sets of parallel inverters will have a resonance peak around $\omega_{\mathrm{R}}$.

Within the frequency interval of $\left[12 \omega_{n}, 40 \omega_{n}\right]$, if the number of inverters is a constant, the values of $\mathrm{d}\left|\Phi_{\text {ind }}(\mathrm{j} \omega)\right| /$ $\mathrm{d} \omega, \mathrm{d}\left|\Phi_{\text {para }}(\mathrm{j} \omega)\right| / \mathrm{d} \omega$ and $\mathrm{d}\left|\Phi_{\text {series }}(\mathrm{j} \omega)\right| / \mathrm{d} \omega$ occur 2,2 , and 1 times signum changes, respectively. It indicates that $\left|\Phi_{\text {ind }}(\mathrm{j} \omega)\right|,\left|\Phi_{\text {para }}(\mathrm{j} \omega)\right|$ and $\left|\Phi_{\text {series }}(\mathrm{j} \omega)\right|$ have 2,2 , and 1 maxima within this frequency interval, respectively. This also indicates that $\Phi_{\text {ind }}(\mathrm{j} \omega), \Phi_{\text {para }}(\mathrm{j} \omega)$, and $\Phi_{\text {series }}(\mathrm{j} \omega)$ have 2, 2, 1 intrinsic resonance peaks, respectively. 
Within the frequency interval of $\left(0,12 \omega_{\mathrm{n}}\right), \mathrm{d}\left|\Phi_{\text {ind }}(\mathrm{j} \omega)\right| /$ $\mathrm{d} \omega, \mathrm{d}\left|\Phi_{\text {para }}(\mathrm{j} \omega)\right| / \mathrm{d} \omega$, and $\mathrm{d}\left|\Phi_{\text {series }}(\mathrm{j} \omega)\right| / \mathrm{d} \omega$ obviously occur 6, 6, 1 times sign changes, respectively. It indicates that 6, 6,1 extrinsic resonance peaks exist in $\Phi_{\text {ind }}(\mathrm{j} \omega), \Phi_{\text {para }}(\mathrm{j} \omega)$, and $\Phi_{\text {series }}(\mathrm{j} \omega)$ respectively. It should be emphasized that the extrinsic resonances is caused by the outer-loop PR controller which exerts resonance effect on the multi-parallel inverters around the selected frequencies. On the contrary, the intrinsic resonance peaks within the interval of $\left[12 \omega_{n}, 40 \omega_{n}\right]$ are caused by the coupling effect of the inverter equivalent output impedances. Thus, the intrinsic resonances inherently exist in multi-parallel inverters system, for any current control schemes. To some extent, the analysis of the intrinsic resonance phenomena possesses universal significance, being also one of the focuses of the rest of the paper.

\subsection{Distribution of resonance peaks}

According to Fig. 5, the frequency distribution of intrinsic resonance peaks for different number of parallel inverters is listed in Table 2. If a single inverter is connected to the grid, the harmonics in $u_{\mathrm{g}}$ and $i_{2}$ around 1280 $\mathrm{Hz}$ will be largely magnified. Furthermore, the individual and series resonance peaks around $1280 \mathrm{~Hz}$ will move toward lower frequency domain along with the increasing in the number of parallel inverters. These moving resonance peaks can be defined as non-fixed peaks. Besides, an additionally fixed individual resonance peak around 1740 $\mathrm{Hz}$ appears when we have more than one inverter. Further, parallel resonances with a fixed peak and a non-fixed peak only appear in case of multiple-parallel inverters, which present the same frequency distribution as the individual resonance. Series resonances have not fixed peaks.

From (7) and Table 2, it can be concluded that the amount of intrinsic resonance peaks of $\Phi_{\text {ind, } m}(\mathrm{j} \omega)$, $\Phi_{\text {para }, m, i}(\mathrm{j} \omega)$, and $\Phi_{\text {series }, m}(\mathrm{j} \omega)$ of the $m^{\text {th }}$ inverter in case of $n(n \geq 2)$ parallel inverters is $2,2(n-1)$, and 1 , respectively. Supposing that each inverter is equivalent, the resonance amplitudes of $\Phi_{\text {ind, } m}(\mathrm{j} \omega), \Phi_{\text {para }, m, i}(\mathrm{j} \omega)$, and $\Phi_{\text {series }, m}(\mathrm{j} \omega)$ in the frequency domain of $\left(\omega_{n}, 40 \omega_{n}\right)$ along with the inverters of $(1,20)$ is depicted in Fig. 6. The simulation parameters are listed in Table 1.

From Fig. 6a and b, a fixed intrinsic peak emerges in both the individual resonance and the parallel resonance around $35^{\text {th }}$ harmonic frequency $(1740 \mathrm{~Hz})$. Note that when increasing in the number of inverters, the amplitude of the individual resonance increases, but, by contrast, the parallel resonance decreases. Besides, when the number of inverters increases, the variation of the non-fixed intrinsic peaks in frequency and amplitude for the three kinds of resonances are summarized as follows: the amplitudes of the non-fixed intrinsic peaks decrease, while the peak frequencies are moving towards low-frequency domain, as shown in Fig. 6. Notice that only non-fixed peak exists in series resonance.

\section{Active damping control design and damping coefficient optimization}

\subsection{Active damping control loop design}

The inner active damping loop introducing the feedback of filter-capacitor current is to emulate a virtual resistance connecting in parallel with the filter capacitor. In order to quantify this physical equivalence, the block diagram from Fig. 3 can be equivalently modified by substituting the bold-line feedback for a dashed-line feedback, as shown in Fig. 7. The feedback coefficient $H_{\mathrm{d}}$ is equal to $K_{\mathrm{PWM}} K_{\mathrm{C}} C_{\mathrm{f}} /$ $L_{1}$ when $R_{1}$ is neglected.

The inner loop, which is composed by $H_{\mathrm{d}}$ and $1 / s C_{\mathrm{f}}$, in Fig. 7 can be simplified as

$G_{d}=\frac{\frac{1}{s C_{\mathrm{f}}}}{1+\frac{K_{\mathrm{PWM}} K_{\mathrm{C}}}{s L_{1}}}=\frac{\frac{1}{s C_{\mathrm{f}}} \frac{L_{1}}{K_{\mathrm{PWM}} K_{\mathrm{C}} C_{\mathrm{f}}}}{\frac{1}{s C_{\mathrm{f}}}+\frac{L_{1}}{K_{\mathrm{PWM}} K_{C} C_{\mathrm{f}}}}=\frac{1}{s C_{\mathrm{f}}} / / \frac{L_{1}}{K_{\mathrm{PWM}} K_{\mathrm{C}} C_{\mathrm{f}}}$

which indicates that the equivalent effect of the active damping loop is to add a virtual resistance equal to $L_{1} /$

Table 2 Frequency distribution of intrinsic resonance peaks along with different number of parallel inverters

\begin{tabular}{|c|c|c|c|c|c|c|}
\hline \multirow[t]{2}{*}{ Number of inverters } & \multicolumn{2}{|c|}{ Individual resonance $\Phi_{\text {ind }, m}\left(i_{2, m}\right)(\mathrm{Hz})$} & \multicolumn{2}{|c|}{ Parallel resonance $\Phi_{\mathrm{para}, m, i}\left(i_{2, i}\right)(\mathrm{Hz})$} & \multicolumn{2}{|c|}{ Series resonance $\Phi_{\text {series }, m}\left(u_{\mathrm{g}}\right)(\mathrm{Hz})$} \\
\hline & Fixed & Non-fixed & Fixed & Non-fixed & Fixed & Non-fixed \\
\hline 1 & & 1280 & & & & 1280 \\
\hline 2 & 1740 & 1120 & 1740 & 1120 & & 1120 \\
\hline 3 & 1740 & 1030 & 1740 & 1030 & & 1030 \\
\hline 4 & 1740 & 969 & 1740 & 969 & & 969 \\
\hline 5 & 1740 & 930 & 1740 & 930 & & 930 \\
\hline 6 & 1740 & 901 & 1740 & 901 & & 901 \\
\hline
\end{tabular}




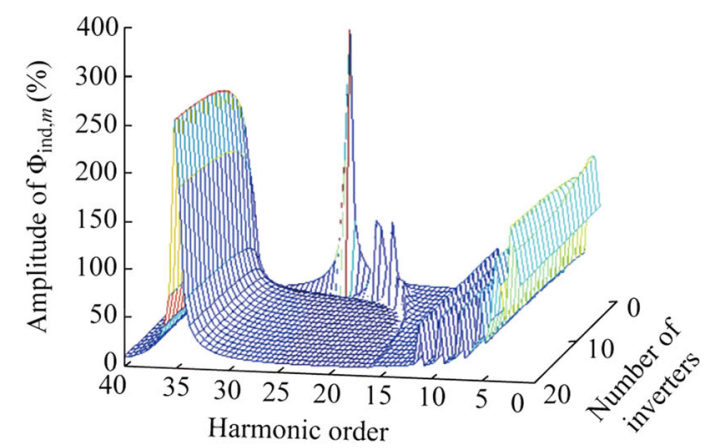

(a) $\Phi_{\text {ind.m }}=\left(K_{\mathrm{C}}=0\right)$

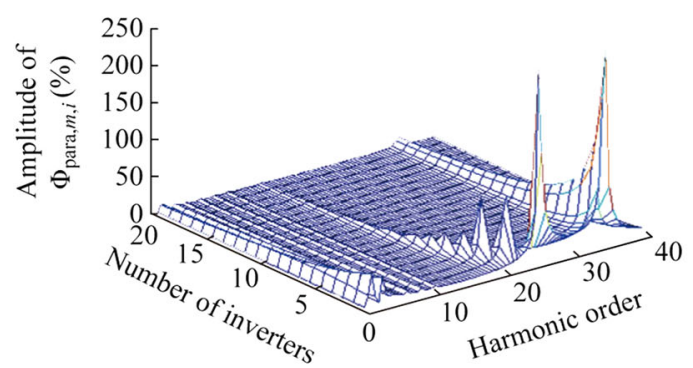

(b) $\Phi_{\text {para }, m, i}=\left(K_{\mathrm{C}}=0\right)$

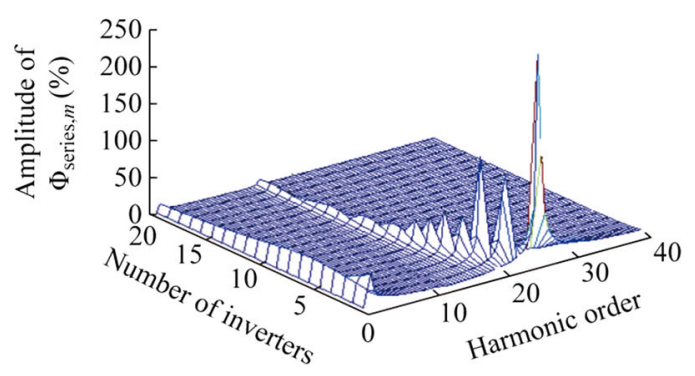

(c) $\Phi_{\text {series }, m}=\left(K_{\mathrm{C}}=0\right)$

Fig. 6 Resonance amplitudes

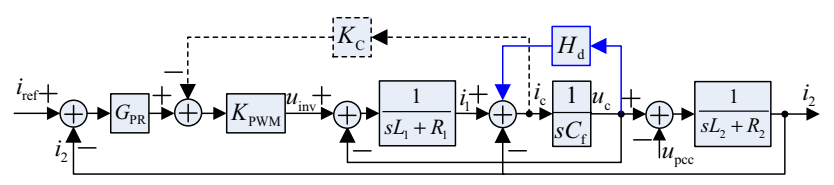

Fig. 7 Equivalent control block of filter-capacitor current feedback loop

$\left(K_{\mathrm{PWM}} K_{\mathrm{C}} C_{\mathrm{f}}\right)$ connecting in parallel with $C_{\mathrm{f}}$. From the frequency response viewpoint, a virtual resistance connecting in parallel with the filter capacitor is considered as a good damping method. The reason is that it has the ability to damp the resonance peak without deteriorating the filter dynamic in low or high frequency domains.

\subsection{Chosen an optimal coefficient of damping feedback}

Then, an intuitive approach to choose an optimal coefficient of damping feedback $K_{\mathrm{C}}$ is proposed. Taking two

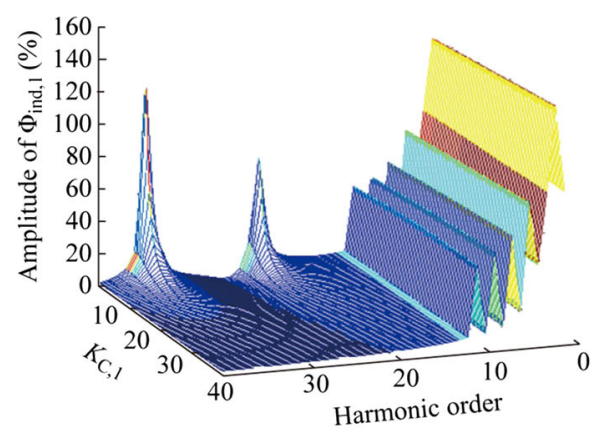

(a) $\Phi_{\text {ind, }}$

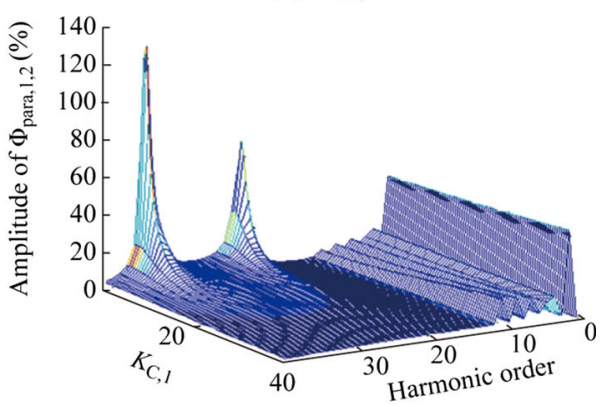

(b) $\Phi_{\text {para, } 1.2}$

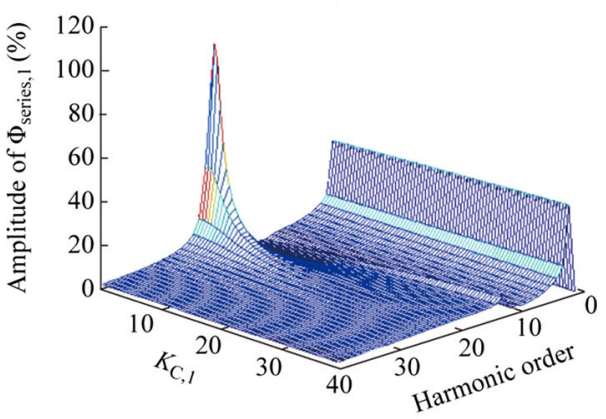

(c) $\Phi_{\text {series. } 1}$

Fig. 8 Amplitude-frequency responses

parallel inverters for example, Fig. 8 shows the amplitudefrequency responses of $\Phi_{\text {ind, } 1}, \Phi_{\text {para, } 1,2}$, and $\Phi_{\text {series,1 }}$ of the $1^{\text {st }}$ inverter in the frequency domain of $\left(\omega_{\mathrm{n}}, 40 \omega_{\mathrm{n}}\right)$ along with the growth in value of $K_{\mathrm{C}, 1}$ from 0 to 40 . The simulation parameters are listed in the Table 1. As shown in Fig. 8, the most prominent coupling resonance phenomena will occur in two-parallel-inverter system (worst case).

According to (11), if $K_{\mathrm{C}, 1}=0$, the virtual resistance tends to be infinite, which means that the damping effect is in vain. In this case, the most severe intrinsic peaks will appear in the individual, parallel, and series resonances, as shown in Fig. 8. The amplitudes of $\Phi_{\text {ind, } 1}$ around the $21^{\text {st }}$ and $35^{\text {th }}$ harmonic frequencies are about $79 \%$ and $130 \%$, respectively; the amplitudes of $\Phi_{\text {para, } 1,2}$ around $21^{\text {st }}$ and $35^{\text {th }}$ harmonic frequencies are about $68 \%$ and $129 \%$, respectively; and the amplitude of $\Phi_{\text {series, } 1}$ around the $21^{\text {st }}$ harmonic frequency is about $96 \%$. 
Table 3 Resonance peak amplitudes of two-parallel-inverter system when $K_{\mathrm{C}, 1}=25.1$

\begin{tabular}{lll}
\hline Type & \multicolumn{2}{l}{ Peak amplitudes $(\%)$} \\
\cline { 2 - 3 } & $22^{\text {nd }}$ & $35^{\text {th }}$ \\
\hline Individual resonance $\Phi_{\text {ind }, 1}$ & 5.763 & 4.048 \\
Parallel resonance $\Phi_{\text {para }, 2}$ & 3.747 & 3.267 \\
Series resonance $\Phi_{\text {series }, 1}$ & 5.618 & 3.416 \\
\hline
\end{tabular}

With the growth in value of $K_{\mathrm{C}, 1}$, the amplitudes of intrinsic resonance peaks are drastically decreased. If the value of $K_{\mathrm{C}, 1}$ increases up to 25.1, all the peak amplitudes of intrinsic resonances reduce to $6 \%$ or less, as listed in Table 3.

If the value of $K_{\mathrm{C}, 1}$ continues increasing $\left(K_{\mathrm{C}, 1}>25.1\right)$, the attenuation of intrinsic resonance peaks around $21^{\text {st }}$ and $35^{\text {th }}$ harmonic frequencies tends to be moderate. Meanwhile, the peak amplitude of $\Phi_{\text {series, } 1}$ around $13^{\text {th }}$ harmonic frequency gently increases. Further, if $K_{\mathrm{C}, 1}$ increases up to 39.6 , the amplitude will slightly raise up to $8.6 \%$. The variation of $K_{\mathrm{C}, 1}$ has less influence over the peak amplitudes of the extrinsic resonances, which is a result of the decoupling control effect between the outer-loop PR controller and the inner-loop feedback.

Based on foregoing analysis, $K_{\mathrm{C}}=25.1$ is the optimal choice for each single inverter in order to fulfill the demand frequency-domain responses.

\section{Simulations and experiments}

To verify effectiveness of the proposed modeling and method, several cases including 2, 3, and 6 inverters are simulated by MATLAB simulation. To confirm the feasibility of the damping parameter optimization, all the simulation cases are comparatively conducted under two conditions: $K_{\mathrm{C}}=1$ and $K_{\mathrm{C}}=25.1$. The rated power of each inverter is $2 \mathrm{~kW}$. The power stage and control parameters are listed in Table 1.

\subsection{Individual resonance}

In order to show the movement of the individual resonance peak in frequency domain along with the variation in the number of inverters, the cases of 2, 3, and 6 parallel inverters are considered. When the amplitude of the $1^{\text {st }}$ inverter reference current $i_{\text {ref, } 1}$ achieves $12 \mathrm{~A}$ from $6 \mathrm{~A}$ at $0.405 \mathrm{~s}$, the transient waveforms of the $1^{\text {st }}$ inverter's gridside current $i_{2,1}$ and its frequency spectrum with $K_{\mathrm{C}}=1$ are depicted in Fig. 9.
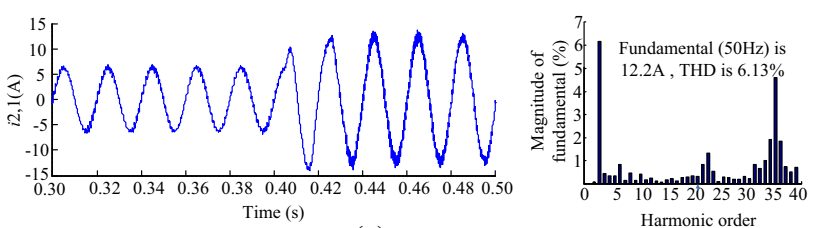

(a) 2 parallel inverters

Harmonic order
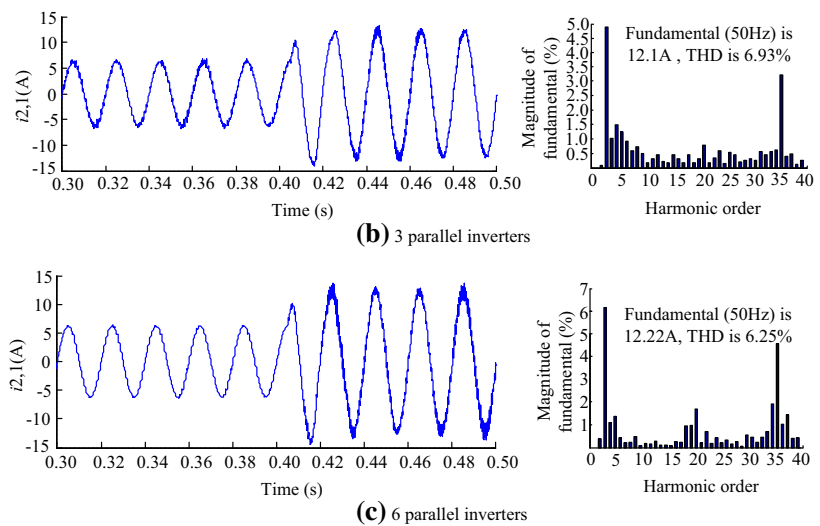

Fig. 9 Simulation waveforms of the $1^{\text {st }}$ inverter grid-side current and its frequency spectrum during the transient of its amplitude of reference current $\left(K_{\mathrm{C}}=1\right)$

There are two individual resonance peaks (a fixed and an unfixed) exist in the case of 2, 3, and 6 parallel inverters, as shown in Fig. 9a-c, and their unfixed peaks are around $22^{\text {nd }}(1120 \mathrm{~Hz}), 20^{\text {th }}(1030 \mathrm{~Hz})$, and $18^{\text {th }}(901 \mathrm{~Hz})$ harmonic frequency, respectively. Their fixed peaks are permanently located around $35^{\text {th }}(1740 \mathrm{~Hz})$ harmonic frequency. The peak movements of the individual resonances shown in Fig. 9 are consistent with the resonance frequencies listed in the Table 2.

Under the condition of $K_{\mathrm{C}}=25.1$, the $1^{\text {st }}$ inverter gridside currents $i_{\text {ref, } 1}$ during the transient of its amplitude of reference current suddenly changing from $6 \mathrm{~A}$ to $12 \mathrm{~A}$ at $0.405 \mathrm{~s}$, are depicted in Fig. 10. Compared with the case of $K_{\mathrm{C}}=1$, the $1^{\text {st }}$ inverter grid-side current $i_{\text {ref, } 1}$ depicted in Fig. 10 apparently presents less current distortion associated with high-frequency harmonic during the transient. In other words, the case of $K_{\mathrm{C}}=25.1$ presents better damping effect.

\subsection{Parallel resonance}

To show the peak movements of the paralle

1 resonance in the frequency domain when the number of inverters change, the cases of 2, 3, and 6 parallel inverters are investigated, respectively. These cases are simulated under the condition of $K_{\mathrm{C}}=1$. When the amplitude of the $2^{\text {nd }}$ inverter reference current $i_{\text {ref,2 }}$ suddenly changes from 6 A to $12 \mathrm{~A}$ at $0.405 \mathrm{~s}$, the transient waveforms of the $1^{\text {st }}$ inverter's grid-side current $i_{\text {ref, } 1}$ and its frequency spectrum are depicted in Fig. 11. 

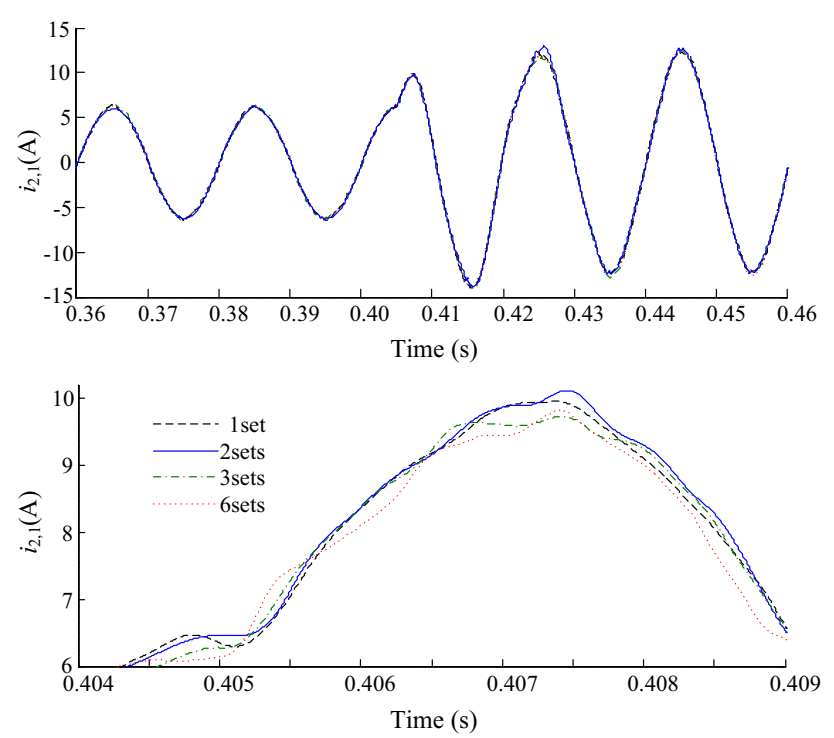

Fig. 10 Simulation waveforms of $1^{\text {st }}$ inverter grid-side current during its amplitude of reference current $\left(K_{\mathrm{C}}=25.1\right)$

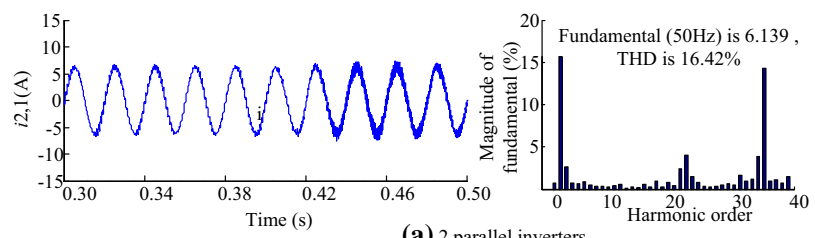

(a) 2 parallel inverters

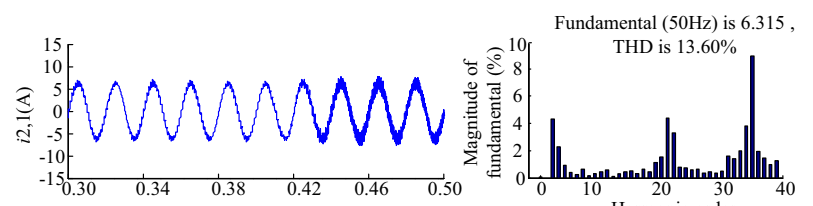

(b) 3 parallel inverters

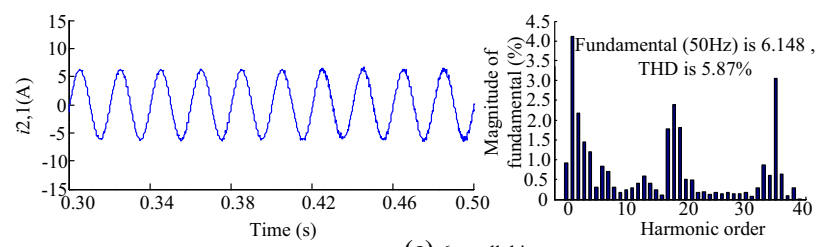

(c) 6 parallel inverters

Fig. 11 Simulation waveforms of the $1^{\text {st }}$ inverter grid-side current and its harmonic spectrum during the transient of the amplitude of the $2^{\text {nd }}$ inverter reference current $\left(K_{\mathrm{C}}=1\right)$

Two parallel resonance peaks including a fixed and an unfixed ones exist in the cases of 2, 3, 6 parallel inverters, as shown in Fig. 11a-c. And the unfixed peaks are around $22^{\text {nd }}(1120 \mathrm{~Hz}), 20^{\text {th }}(1030 \mathrm{~Hz})$, and $18^{\text {th }}(901 \mathrm{~Hz})$ harmonic frequency, respectively. The fixed peaks are permanently located around $35^{\text {th }}(1740 \mathrm{~Hz})$ harmonic frequency.

Under the condition of $K_{\mathrm{C}}=25.1$, the $1^{\text {st }}$ inverter's grid-side currents $i_{\text {ref, } 1}$ during the transient of the amplitude
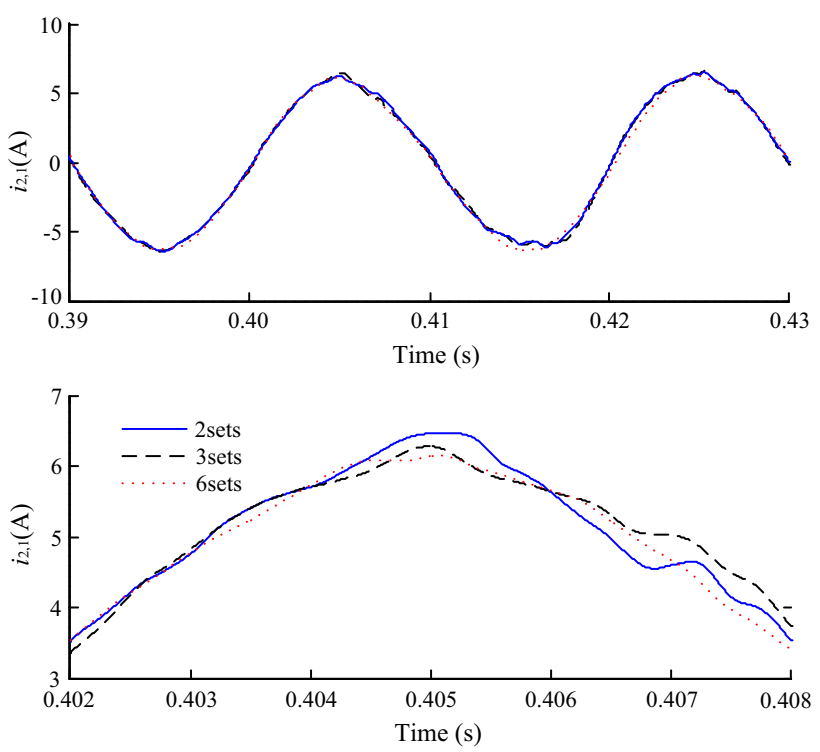

Fig. 12 Simulation waveforms of the $1^{\text {st }}$ inverter grid-side current during the transient of the amplitude of the $2^{\text {nd }}$ inverter reference current $\left(K_{\mathrm{C}}=25.1\right)$

of the $2^{\text {nd }}$ inverter reference current $i_{\text {ref,2 }}$ changing from 6 A to $12 \mathrm{~A}$ at $0.405 \mathrm{~s}$ are depicted in Fig. 12. Compared with the case of $K_{\mathrm{C}}=1$, the $1^{\text {st }}$ inverter's grid-side current $i_{\text {ref }, 1}$ is hardly influenced during the transient. This decoupling effect is going to enhance with the growth in number of parallel inverters. As shown in Fig. 12, the high-frequency ripples during the transient are going to decrease with the growth in the number of parallel inverters.

\subsection{Series resonance}

The output currents of inverters are subjected to fluctuations of power generation, e.g. solar irradiance in case of photovoltaic panels. In order to simulate the practical condition of a parallel system that consists of 6 inverters, the amplitudes of the $1^{\text {st }}$ to the $6^{\text {th }}$ inverter reference currents are $6,6,8,7,5,8 \mathrm{~A}$, respectively. A local weak grid containing $0.32 \%$ of $21^{\text {st }}$ background harmonic voltage is also simulated.

To simulate the transient of several inverters shutting down by sudden changing the local irradiance, the parallel system operates in the following time sequence: before 0.4 s, 6 inverters operate in parallel; next, the $4^{\text {th }}$ to $6^{\text {th }}$ inverters are shut down at $0.4 \mathrm{~s}$; then, the $3^{\text {rd }}$ inverter is shut-down at $0.44 \mathrm{~s}$; finally, the $2^{\text {nd }}$ inverter is shut-down at $0.48 \mathrm{~s}$, meanwhile, only the $1^{\text {st }}$ inverter is still operating.

The cases are simulated under the condition of $K_{\mathrm{C}}=1$. The $1^{\text {st }}$ inverter's grid-side current $i_{\text {ref, } 1}$ and its frequency spectrum during the transient are depicted in Fig. 13. 

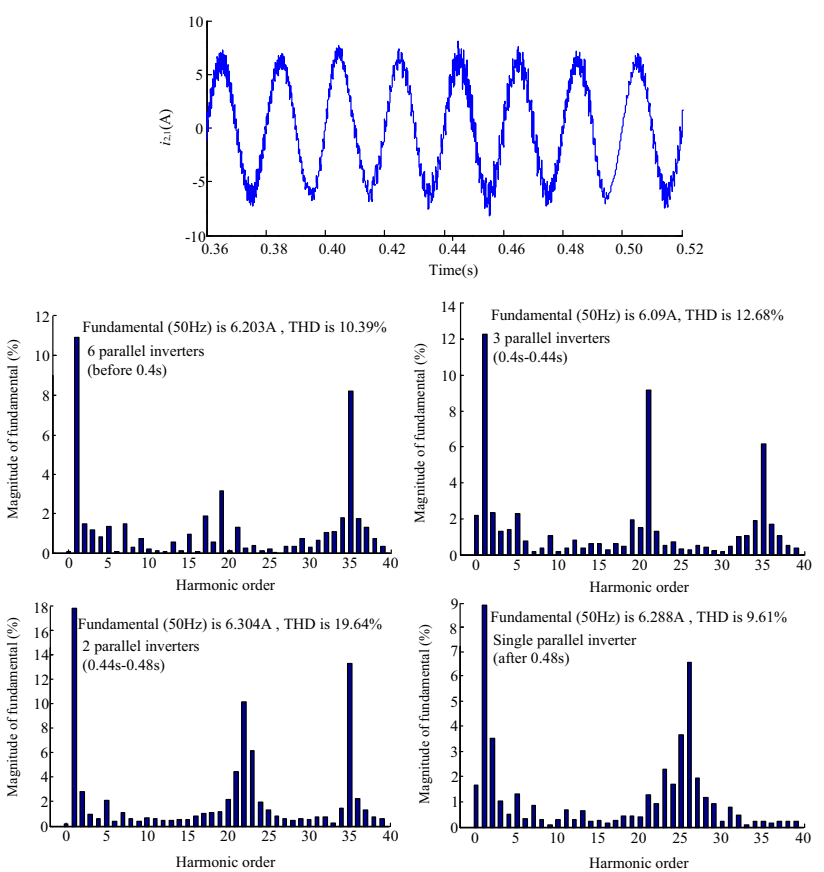

Fig. 13 Simulation waveforms of the $1^{\text {st }}$ inverter grid-side current and its frequency spectrum during the transient of other inverters shutting down in the time sequence $\left(K_{\mathrm{C}}=1\right)$

According to Table 2, the series resonance peaks in the cases of a single inverter and 2, 3, and 6 parallel inverters are around 1280, 1120, 1030, $901 \mathrm{~Hz}$, respectively. Although, the $1^{\text {st }}$ inverter does connect to the grid during the whole transient period, the high-frequency ripple of its grid-side current $i_{2,1}$ occurs significant variation along with the aforementioned time sequence. The reason for this ripple variation is that the peak frequency of series resonance moves toward a higher frequency domain when the number of operating inverters decreases, as shown in Figs. 13. Due to the series resonance peak of 2 parallel inverters around $23^{\text {rd }}$ harmonic frequency, the $21^{\text {st }}$ background harmonic voltage dramatically distorts the $1^{\text {st }}$ inverter's grid-side current $i_{2,1}$ and its THD is up to $19.64 \%$.

Figure 14 shows the $1^{\text {st }}$ inverter's grid-side current $i_{\text {ref, } 1}$ during the transient of other inverters shutting down in the same time sequence. Compared with $K_{\mathrm{C}}=1$, the $1^{\text {st }}$ inverter's grid-side current $i_{2,1}$ is hardly influenced during the transient. Moreover, in this case the grid background harmonic voltage has less influence on the $1^{\text {st }}$ inverter's grid-side current $i_{\text {ref,1. }}$.

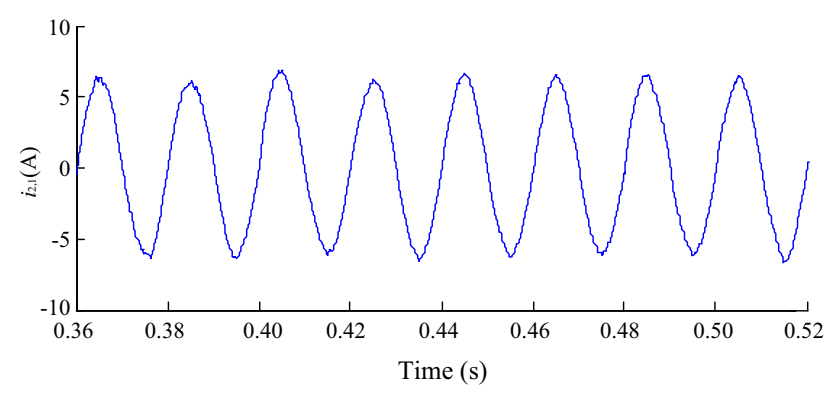

Fig. 14 Simulated waveform of the $1^{\text {st }}$ inverter grid-side current during the transient of other inverters shutting down in the time sequence $\left(K_{\mathrm{C}}=25.1\right)$

\subsection{Experimental verification}

A prototype of three-parallel-inverter system is built. The rated power of each single-phase inverter is $2 \mathrm{~kW}$. The switching frequency is $12.8 \mathrm{kHz}$. The grid currents of 3 parallel inverters flow to the grid. The two cases $\left(K_{\mathrm{C}}=5\right.$ and $K_{\mathrm{C}}=25.1$ ) are comparatively investigated and the parameters are same as in the simulation (see Table 1).

When the amplitude of the $1^{\text {st }}$ inverter's grid-side current suddenly changes from $6 \mathrm{~A}$ to $12 \mathrm{~A}$, the experimental waveforms of the $1^{\text {st }}$ and $2^{\text {nd }}$ inverters' grid currents and grid voltage, and the frequency spectrum diagrams of the $2^{\text {nd }}$ inverter grid-side current are shown in Fig. 15. In case of $K_{\mathrm{C}}=5$, the two inverters' grid-side currents apparently contain high-frequency ripples, which significantly increase after the transient. The $2^{\text {nd }}$ inverter's grid-side current presents severe disturbances at the PCC point where the amplitude of the $1^{\text {st }}$ inverter's grid-side current step change occurs. The THD of the $2^{\text {nd }}$ inverters' grid-side current is up to $9.2 \%$ after the transient. On the contrary, in case of $K_{\mathrm{C}}=25.1$, the high-frequency ripples drastically decrease before and during the transient. The $2^{\text {nd }}$ inverter's grid-side current presents little disturbances caused by the step change of the amplitude of the $1^{\text {st }}$ inverter's grid-side current. The THD of the $2^{\text {nd }}$ inverters' grid-side current is only $3.9 \%$ after the transient.

When the $1^{\text {st }}$ inverter is disconnected, the $1^{\text {st }}$ and $2^{\text {nd }}$ inverter grid-side current and grid voltages during the transient are depicted in Fig. 16. In the case of $K_{\mathrm{C}}=5$, the $2^{\text {nd }}$ inverter grid-side current contains apparent high-frequency ripples after the $1^{\text {st }}$ inverter shutting down. The current ripples are caused by the grid background harmonic voltage. On the contrary, in the case of $K_{\mathrm{C}}=25.1$, the transient of the $1^{\text {st }}$ inverter's shutting down presents less influence over the $2^{\text {nd }}$ inverter grid-side current. 

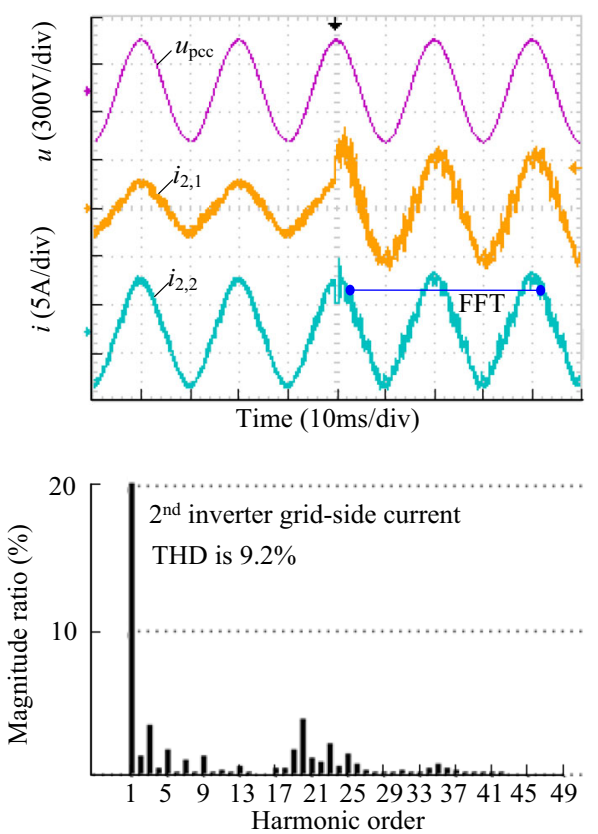

(a) $K_{\mathrm{C}}=5$
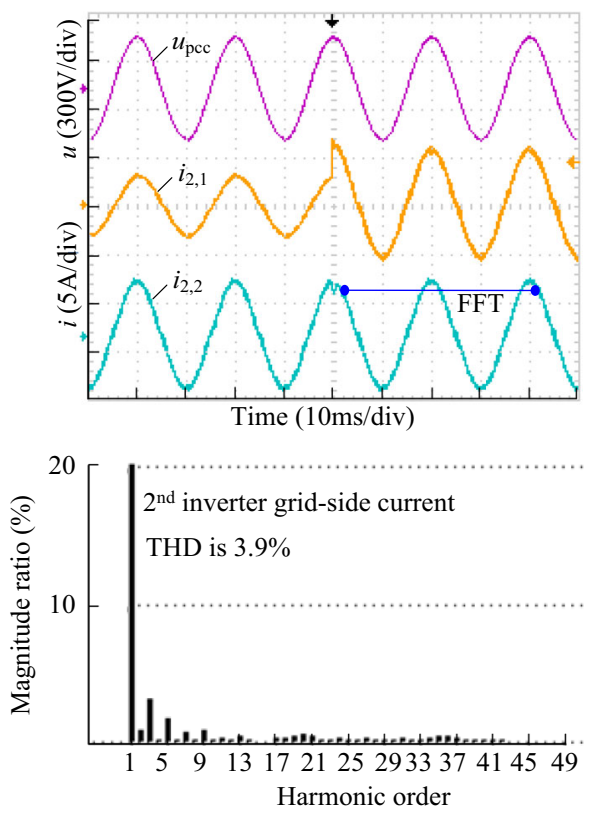

(b) $K_{\mathrm{C}}=25.1$

Fig. 15 Experimental waveforms during the transient of the amplitude of the $1^{\text {st }}$ inverter reference current

\section{Conclusions}

The resonances in multi-parallel inverters in microgrid operating in grid-connected mode can be classified into two types: intrinsic resonance and extrinsic resonance. The former exists permanently in the parallel-inverters system,

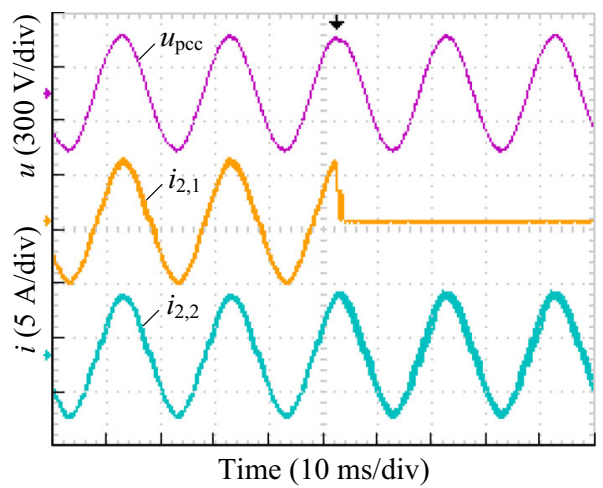

(a) $K_{\mathrm{C}}=5$

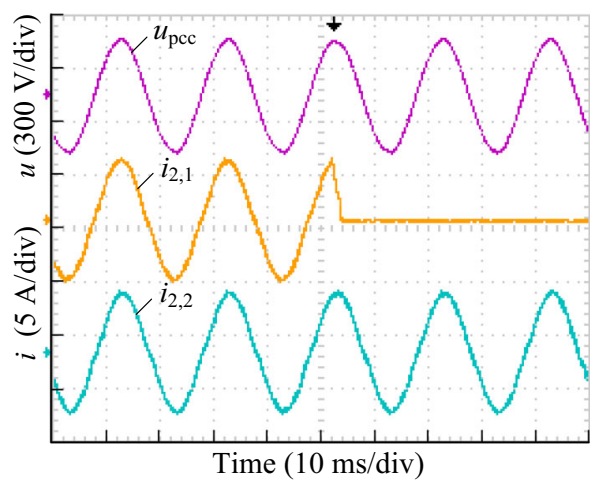

(b) $K_{\mathrm{C}}=25.1$

Fig. 16 Experimental waveforms during the transient of the $1^{\text {st }}$ inverter shutting down

independently from the chosen controller. On the contrary, the extrinsic resonance is caused by the different control modes of the inverters. And the distributions of intrinsic resonances along with the growth in the number of inverters have been explicitly investigated by using mathematical approach. The equivalent coupling circuit of multi-parallel inverters which can explain the coupling resonance phenomena among parallel inverters has been figured out. Besides, the intuitive way to choose an optimal damping parameter has been proposed in this paper, which can easily locate the optimal range of the control parameter. Simulations and experimental results have been performed in order to validate the proposed model and control approaches. The approach is useful to mitigate coupling resonances in multi-parallel inverters in microgrid operating in grid-connected mode.

Acknowledgment This work was supported by National Natural Science Foundation of China (No. 51237003 and No. 51577056), the Hunan Provincial Innovation Foundation for Postgraduate (No. CX2015B084), the Fundamental Research Funds for the Central Universities (No. 2015-001) and the Scientific Program of State Grid Corporation of China (No. 521820140018). 
Open Access This article is distributed under the terms of the Creative Commons Attribution 4.0 International License (http:// creativecommons.org/licenses/by/4.0/), which permits unrestricted use, distribution, and reproduction in any medium, provided you give appropriate credit to the original author(s) and the source, provide a link to the Creative Commons license, and indicate if changes were made.

\section{References}

[1] Wu MF, Lu D (2014) Active stabilization methods of electric power systems with constant power loads: a review. J Mod Power Syst Clean Energy 2(3):233-243. doi:10.1007/s40565014-0066-y

[2] Wan C, Huang M, Tse CK et al (2013) Stability of interacting grid-connected power converters. J Mod Power Syst Clean Energy 1(3):249-257. doi:10.1007/s40565-013-0034-y

[3] Ding GQ, Wei R, Zhou K et al (2015) Communication-less harmonic compensation in a multi-bus microgrid through autonomous control of distributed generation grid-interfacing converters. J Mod Power Syst Clean Energy 3(4):597-609. doi:10.1007/s40565-015-0158-3

[4] Zhao HR, Wu QW, Wang CS et al (2015) Fuzzy logic based coordinated control of battery energy storage system and dispatchable distributed generation for microgrid. J Mod Power Syst Clean Energy 3(3):422-428. doi:10.1007/s40565-0150119-x

[5] Guerrero JM, Matas J, de Vicuna LG et al (2007) Decentralized control for parallel operation of distributed generation inverters using resistive output impedance. IEEE Trans Ind Electron 54(2):994-1004

[6] Kim JH, Guerrero JM, Rodriguez P et al (2011) Mode adaptive droop control with vitual output impedances for an inverterbased flexible AC microgrid. IEEE Trans Power Electron 26(3):689-701

[7] Timbus A, Liserre M, Teodorescu R et al (2009) Evaluation of current controllers for distributed power generation systems. IEEE Trans Power Electron 24(3):654-664

[8] Luo A, Chen YD, Shuai ZK et al (2013) An improved reactive current detection and power control method for single-phase photovoltaic grid-connected DG system. IEEE Trans Energy Convers 28(4):823-831

[9] Chen YD, Luo A, Shuai ZK et al (2013) Robust predictive dualloop control strategy with reactive power compensation for single-phase grid-connected distributed generation system. IET Power Electron 6(7):1320-1328

[10] Guerrero JM, de Vicuna LG, Matas J et al (2005) Output impedance design of parallel-connected UPS inverters with wireless load-sharing control. IEEE Trans Ind Electron 52(4):1126-1135

[11] Chen ZY, Luo A, Wang HJ et al (2015) Adaptive sliding-mode voltage control for inverter operating in islanded mode in microgrid. Int J Electr Power Energ Syst 66:133-143

[12] Twining E, Holmes DG (2003) Grid current regulation of a three-phase voltage source inverter with an LCL input filter. IEEE Trans Power Electron 18(3):888-895

[13] He JW, Li YW, Bosnjak D et al (2013) Investigation and active damping of multiple resonances in a parallel-inverter-based microgrid. IEEE Trans Power Electron 28(1):234-245

[14] Mohamed YA-RI, Zeineldin HH, Salama MMA et al (2012) Seamless formation and robust control of distributed generation microgrids via direct voltage control and optimized dynamic power sharing. IEEE Trans Power Electron 27(3):1283-1294
[15] Dannehl J, Fuchs FW, Hansen S et al (2010) Investigation of active damping approaches for PI-based current control of gridconnected pulse width modulation converters with LCL filters. IEEE Trans Ind Electron 46(4):1509-1517

[16] Agorreta JL, Borrega M, Lopez J et al (2011) Modeling and control of $N$-paralleled grid-connected inverters with LCL filter coupled due to grid impedance in PV plants. IEEE Trans Power Electron 26(3):770-785

[17] Enslin JHR, Heskes PJM (2004) Harmonic interaction between a large number of distributed power inverters and the distribution network. IEEE Trans Power Electron 19(6):1586-1593

[18] Shuai ZK, Liu DG, Shen J et al (2014) Series and parallel resonance problem of wideband frequency harmonic and its elimination strategy. IEEE Trans Power Electron 29(4):1941-1952

Zhiyong CHEN was born in Hunan, China, in 1985. He received the B.S. degree in automation from Xiangtan University, Xiangtan, China, in 2007, and received the M.S. degree in power electronics and power drives in 2010 . He is currently pursuing the $\mathrm{Ph} . \mathrm{D}$. degree in electrical engineering at Hunan University, Changsha, China. From 2010 to 2012, he was employed as an electrical and marketing manager in XEMC New Energy Co., Ltd., Xiangtan. His research interests include power electronics of microgrid, distributed generation.

Yandong CHEN was born in Hunan, China, in 1979. He received the B.S. and M.S. degree in instrument science and technology from Hunan University, Changsha, China, in 2003 and 2006, respectively, and the $\mathrm{Ph} . \mathrm{D}$. degree in electrical engineering from Hunan University, Changsha, China, in 2014. He has been an Assistant Professor with the National Electric Power Conversion and Control Engineering Technology Research Center, Hunan University, Changsha. His research interests include power electronics for microgrid, distributed generation, power quality, and energy storage. He is a member of IEEE Power Electronics Society.

Josep M. GUERRERO received the B.S. degree in telecommunications engineering, the M.S. degree in electronics engineering, and the $\mathrm{Ph} . \mathrm{D}$. degree in power electronics from the Technical University of Catalonia, Barcelona, in 1997, 2000 and 2003, respectively. Since 2011, he has been a Full Professor with the Department of Energy Technology, Aalborg University, Denmark, where he is responsible for the Microgrid Research Program. From 2012 he is a guest Professor at the Chinese Academy of Science and the Nanjing University of Aeronautics and Astronautics; from 2014 he is chair Professor in Shandong University; and from 2015 he is a distinguished guest Professor in Hunan University. His research interests is oriented to different microgrid aspects, including power electronics, distributed energy-storage systems, hierarchical and cooperative control, energy management systems, and optimization of microgrids and islanded minigrids. Prof. Guerrero is an Associate Editor for the IEEE Transactions on Power Electronics, the IEEE Transactions on Industrial Electronics, and the IEEE Industrial Electronics Magazine, and an Editor for the IEEE Transactionas on Smart Grid and IEEE Transactions on Energy Conversion. He has been Guest Editor of the IEEE Transactions on Power Electronics Special Issues: Power Electronics for Wind Energy Conversion and Power Electronics for Microgrids; the IEEE Transactions on Inductrial Electronics Special Sections: Uninterruptible Power Supplies systems, Renewable Energy Systems, Distributed Generation and Microgrids, and Industrial Applications and Implementation Issues of the Kalman Filter; and the IEEE Transactions on Smart Grid Special Issue on Smart DC Distribution Systems. He was the chair of the Renewable Energy Systems Technical Committee of the IEEE Industrial Electronics 
Society. In 2014 and 2015 he was awarded by Thomson Reuters as Highly Cited Researcher, and in 2015 he was elevated as IEEE Fellow for his contributions on "distributed power systems and microgrids."

Huimin KUANG was born in Heze, China, 1991. She received B.S degree from Hunan University, Changsha, China in 2013. She is currently working toward the M.S degree at Hunan University, engaging in power quality, renewable energy and power system analysis.

Yuan HUANG was born in Hunan, China, in 1981. He received the B.S. degree in automation from Hunan University of Science and Technology, China, in 2002, and received the M.S. degree in control theory and control engineering from Hunan University, China, in 2006. She is currently pursuing the Ph.D degree in electrical engineering at Hunan University, China. From 2006 to 2011, she was employed as an instructor in Information and Electrical Engineering, Hunan University of Science and Technology. His research interests include power electronics of microgrid, distributed generation.
Leming ZHOU was born in Hunan, China, in 1989. He received the B.S. degree in electrical engineering from Hunan University, Changsha, China, in 2011. He is currently pursuing the Ph.D. degree in electrical engineering at Hunan University, Changsha, China. His research interests include power electronics for microgrid, distributed generation and power quality.

An LUO was born in Changsha, China, in 1957. He received the B.S. and M.S. degrees in industrial automation from Hunan University, Changsha, in 1982 and 1986, respectively, and the Ph.D. degree in fluid power transmission and control from Zhejiang University, Hangzhou, China, in 1993. Between 1996 and 2002, he was a Professor with Central South University. Since 2003, He has been a Professor with the College of Electrical and Information Engineering, Hunan University. He has published over 300 articles. His research interests include distributed generation system, and power quality control. Prof. Luo is a senior member of IEEE Power Electronics Society. 